\title{
Objective versus Subjective Cognitive Functioning in Patients with Obstructive Sleep Apnea
}

\author{
Chang-Wei Chen, Chien-Ming Yang* and Ning-Hung Chen
}

Department of Psychology/The Research Center for Mind, Brain, \& Learning National Chengchi University 64, Sec. 2, Chih-Nan Rd. Taipei, Taiwan 116

\begin{abstract}
Study objectives: Previous studies have found that patients' neurocognitive functions were affected by OSA symptoms. However, no study has focused on the subjective awareness of cognitive impairments. This study used a subjective rating scale to evaluate OSA patient perceptions of their cognitive impairments, and explore the relationship between subjective and objective cognitive functions.

Methods: An independent-group design was used to compare objective and subjective cognitive performance in both the OSA and control groups. An experimental group of 19 male OSA patients and a control group of 19 normal subjects matched in age and education participated in the study. A neurocognitive test battery that measures attention, memory and executive functions, and the SCIRS (Subjective Cognitive Impairment Rating Scale) that measures subjective perception of cognitive impairments were used.

Results: On the neurocognitive test measures, OSA patients demonstrated decreased performance on memory and executive function. On the subjective measures, OSA patients reported a mild to moderately negative impact on attention, memory, and emotional control due to OSA.

Conclusions: The results show that OSA patients may not be fully aware of their cognitive impairments, especially with regard to their executive functions. The inconsistency suggests that including neurocognitive tests in the evaluation of sleep-related breathing disorders may provide useful information that cannot be obtained through clinical interviews.
\end{abstract}

Keywords: Obstructive sleep apnea, Neurocognitive test battery, Subjective and objective cognitive functions.

\section{INTRODUCTION}

Obstructive sleep apnea (OSA) is characterized by episodes of complete or partial pharyngeal obstruction during sleep and is associated with frequent arousals and intermittent hypoxemia $[1,2]$. OSA is highly prevalent and affects the physical and psychological well-being of the patients. According to epidemiological data, $2 \%$ of females and $4 \%$ of males suffer from OSA in Western countries [3]. East Asian populations have a similar respiratory disturbance index (RDI) but relatively smaller body mass index (BMI) than Western populations. Patients with OSA symptoms are also at a higher risk of other problems during periods of wakefulness, of which the most significant are health-related problems, drowsiness and neurocognitive impairments [4]. The neurocognitive dysfunctions have been brought to the attention of clinicians and researchers because they may have a major impact on the individual's daily activities and occupational safety.

Previous studies have used different neurocognitive tests to examine patients' areas of functioning affected by OSA. The impact of the cognitive deficits may be easily identified

*Address correspondence to this author at the Department of Psychology/The Research Center for Mind, Brain, \& Learning National Chengchi University 64, Sec. 2, Chih-Nan Rd. Taipei, Taiwan 116;

Tel: 886-2-29387383; 886-2-29393091; Ext: 62412; Fax: 886-2-29390644; E-mail: dryangcm@gmail.com: yangcm@nccu.edu.tw in those with a higher apnea-hypopnea index and greater hypoxemia. Although results from previous studies are not all consistent, there seems to be more evidence to support significant deficits in cognitive processing $[2,5]$, sustained attention [6,7] and executive function [8-11] in patients with more severe OSA symptoms. More specifically, impaired cognitive processing is reflected by a slowing of reaction time and increased errors. Deficient sustained attention, or what some authors call vigilance, is reflected in an inability to maintain attention over time, therefore demonstrating a slowing of response time, and increasing lapses and false responses as the task is prolonged. Impaired executive function is reflected in problems with information manipulation, inadequate planning, poor judgment, poor decision-making, inflexibility, impulsivity and difficulty maintaining motivation. All the above neurocognitive problems could influence patients' daily functioning and professional performance. However, in light of the major impact cognitive dysfunction may have, it seems to be ignored by some OSA patients. The association between self-reported cognitive symptoms and performances on objective cognitive tests has been investigated on patients with emotional distress $[12,13]$, head injury $[14,15]$ and insomnia [16]. Some investigators found a significant relationship, but other studies have failed to find an association between objective measures of cognitive dysfunction. Despite inconsistent conclusions on the understanding of objective performance, the subjective rating and the relationship is important and provides useful information 
for future treatment. In clinical observations, the most common complaint of OSA patients is daytime sleepiness and/or fatigue $[4,17,18]$. Complaints about the impact of cognitive dysfunction are less commonly heard.

Although the objective neurocognitive deficits in OSA patients are evident, no study, as far as we know, has focused on the subjective perception of neurocognitive dysfunctions and their relationship with the objective performance of OSA patients. Therefore, the present study examined both the objective and subjective aspects of neurocognitive dysfunctions in OSA patients. We planned to interview OSA patients and discuss their cognitive related symptoms, then use their description to develop Subjective Cognitive Impairment Rating Scale (SCIRS) and to test reliability and validity. The purposes of the present study were: 1) to assess objective cognitive performances in OSA patients using a neurocognitive test battery; 2) to test reliability and validity of SCIRS and measure the OSA patients' subjective cognitive functioning; and 3) to examine the relationship between the objective and subjective measures.

\section{MATERIALS AND METHODOLOGY}

\section{Subjects}

Participants included 19 untreated male OSA patients (age: Mean $\pm \mathrm{SD}=41.72 \pm 7.46$ years; years of education: Mean $\pm \mathrm{SD}=14.67 \pm 1.94$; $\mathrm{BMI}: \mathrm{Mean} \pm \mathrm{SD}=29.06 \pm 4.13$ ), and 19 healthy control male subjects (age: Mean $\pm \mathrm{SD}=41$. $58 \pm 8.28$ years; years of education: $M e a n+\mathrm{SD}=14.74 \pm 1.91$ years; BMI: Mean $\pm \mathrm{SD}=23.76 \pm 2.26$ ). The $\mathrm{OSA}$ subjects were all referred to the sleep lab from the outpatients' clinic in Chang Gung Memorial Hospital. They were all first diagnosed BUT never receive any treatment related to sleep ap-

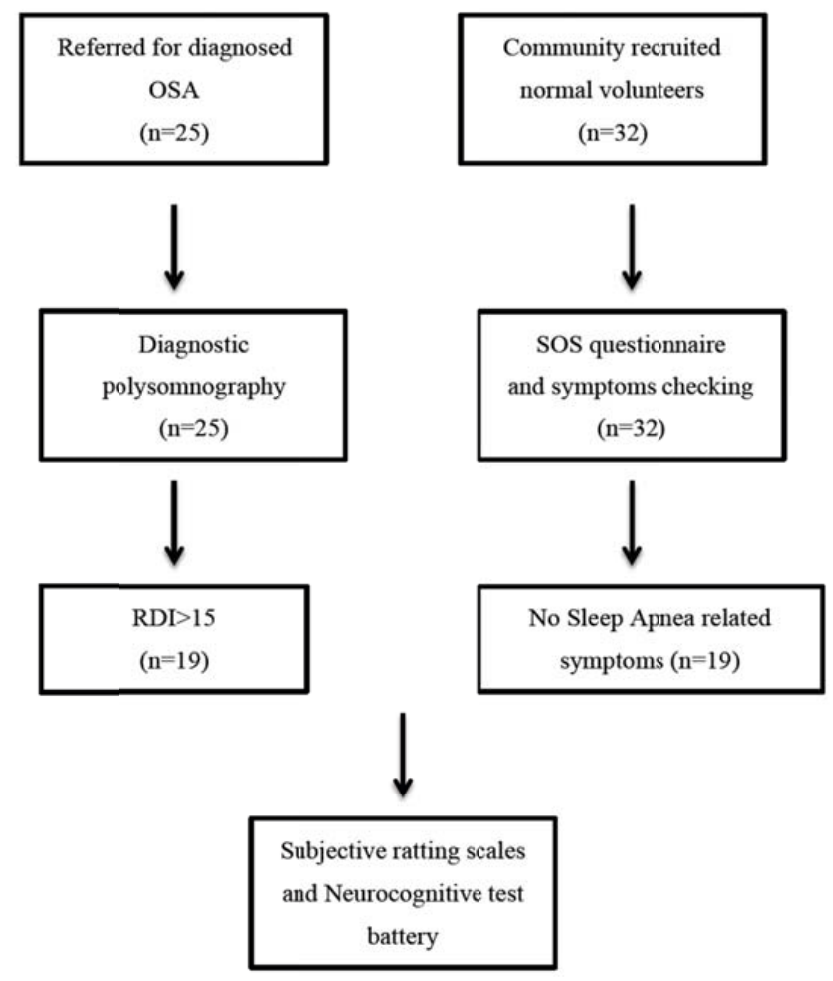

Fig. (1). Research procedures. nea. The control subjects were recruited from the community. There were no significant differences in age, gender and years of education between the two groups. As expected, OSA patients had significant higher BMI than the control subjects $(\mathrm{t}(36)=4.88, \mathrm{p}<.001)$.

The inclusion criteria for participation in both groups were: Age between 30 and 55 years with no major medical disorders. All OSA patients had a polysomnography examination. Previous research has indicated that patients with more severe OSA demonstrated more deficits in neurocognitive functions. Thus, in this study, we included OSA patients with RDI above 15 (RDI: Mean $\pm \mathrm{SD}=59.24 \pm 24.53$ ). The control subjects were screened for sleep disorder breathing (SDB) with the Snore Outcome Study questionnaire (SOS) $[19,20]$ and a report by their bed partners about nighttime SDB-related symptoms and didn't show any OSA related symptom.

All subjects that passed the screening procedures were asked to fill out the subjective rating scales, and then underwent a neurocognitive test battery. We let subjects to decided test administering time according to their subjectively best performance time. The test session began at 9 A.M. and 2 P.M. There were 11 OAS patients and 10 control subjects started tests at 9 A.M., for the rest of the subjects started at 2 P.M. (Fig 1).

\section{MEASURES}

\section{Subjective Cognitive Impairment Rating Scale (SCIRS)}

Since no instrument has been developed to measure the subjective perception of cognitive impairment in OSA patients, we developed the Subjective Cognitive Impairment Rating Scale (SCIRS) [21] to evaluate OSA patients' subjective perception of their cognitive impairment (see Appendix I). To construct the SCIRS, 30 untreated OSA patients were interviewed about their daily life experiences of cognitive problems that may be related to OSA. The descriptions of cognitive problems were first categorized into three groups based on previous research findings of cognitive impairments in OSA; the groups were "attention \& vigilance", "memory \& learning", "abstract thinking \& problem solving." An additional area, "emotional control \& motivation" was added since many patients reported an impact in this domain as well. The descriptions were then integrated into 28 descriptions to serve as the items of the scale. Subjects were asked to rate the impact of OSA on each item with a 5point Likert scale, ranging from 0 (no impact) to 4 (extreme impact). The scale was administered to 88 untreated OSA patients. Internal consistency of the 28 items was good for the total scale (Cronbach's $\alpha=.98$ ) and all four subscales (attention \& vigilance Cronbach's $\alpha=.91$; memory \& learning Cronbach's $\alpha=.93$; abstract thinking \& problem solving Cronbach's $\alpha=.95$; emotional control \& motivation Cronbach's $\alpha=.95)$. In terms of validity, we selected two well validated and popular self-rating scales that were used to measure OSA patients sleepiness (Epworth Sleepiness Scale, ESS) [22] and quality of life (Medical Outcome Study Short Form-36, SF-36) [23] as criteria validity indexes. Table 1 shows the Pearson correlation coefficients between the scores on the SCIRS and the SF-36 and ESS; there was a small to moderate correlation with the ESS and SF-36. There 
Table 1. Pearson Correlation Coefficients Between the Scores on the Subjective Cognitive Impairment Rating Scale (SCIRS) and the Scores on the Medical Outcome Study Short Form-36 (SF-36) and Epworth Sleepiness Scale (ESS)

\begin{tabular}{|c|c|c|c|c|c|}
\hline & \multicolumn{5}{|c|}{ Pearson Correlation Coefficients } \\
\hline ESS & $.414 * *$ & $.332 * *$ & $.363 * *$ & $.350 * *$ & $.373 * *$ \\
\hline \multicolumn{6}{|l|}{ SF-36 } \\
\hline Role-Physical & $-.517 * *$ & $-.498 * *$ & $-.529 * *$ & $-.476^{* *}$ & $-.520 * *$ \\
\hline Bodily Pain & $-.317 * *$ & $-.449 * *$ & $-.381 * *$ & $-.324 * *$ & $-.389 * *$ \\
\hline General Health & $-.485 * *$ & $-.546^{* *}$ & $-.477 * *$ & $-.476 * *$ & $-.520 * *$ \\
\hline Vitality & $-.650 * *$ & $-.672 * *$ & $-.650 * *$ & $-.414 * *$ & $-.410 * *$ \\
\hline Mental Health & $-.610 * *$ & $-.677^{* *}$ & $-.639 * *$ & $-.555^{* *}$ & $-.576^{* *}$ \\
\hline
\end{tabular}

was also a significantly moderate correlation between RDI and total scores of the SCIRS $(\mathrm{r}=.35, \mathrm{p}<.01)$. The discriminate validity is significant in all subscales.

\section{Neurocognitive Test Battery}

A neurocognitive test battery was designed to assess a broad range of cognitive abilities of the subjects. The selected tests were shown to be sensitive to OSA patients' cognitive impairments in previous studies and also demonstrated good reliability and validity in the Chinese-language version. All the tests were widely used and locally validated by some research references.

\section{Multiple Vigilance Test (MVT)}

The MVT was designed to assess vigilance and sustained attention [24]. Subjects were asked to attend to a specific target stimulus, while disregarding distracting non-target stimuli that were displayed on a computer screen. There were 240 stimuli, including 60 target stimuli and 180 nontarget stimuli. The inter-stimulus intervals (ISIs) varied randomly from 4 to 11 seconds. The total test lasted 30 minutes. Subjects' reaction time and the number of misses and false alarms were recorded. The MVT was used to assess subject's fatigue and has shown good reliability and validity [25].

\section{Modified Paced Auditory Serial Addition Test (PASAT)}

The PASAT was developed by Gronwall and colleagues in 1974 to measure attention, concentration, working memory, and speed of information processing. Subjects had to add each new digit to the number immediately preceding it and give the response before the presentation of the next stimulus. In the current study, we used a modified version of the PASAT, with 61 items presented at an ISI of 2.0 seconds. The total correct number and percentage of correct responses were recorded. The PASAT was used to assess subjects' attention process and locally validated [26].

\section{Wechsler Memory Scale (WMS)}

The WMS was designed to measure various aspects of memory function [27]. It consists of 11 subtests (six primary and five optional), and provides eight primary index scores (Auditory Immediate Memory, Visual Immediate Memory, Immediate Memory, Auditory Delayed Memory, Visual Delayed Memory, Auditory Recognition Delayed Memory, General Memory and Working Memory). In the current study, we used four of the primary subtests, Logical Memory, Faces, Verbal Paired Association, and Family Pictures, and calculated seven primary index scores (except the Working Memory Index) for subsequent data analysis. The WMS was locally validated and has shown good reliability and validity [28].

\section{Wechsler Adult Intelligence Scale -- Third Edition (WAIS- III) -- short version}

The purpose of WAIS-III is to provide measures of general intellectual function [27]. The full version of the test consists of 11 subtests and can generate Verbal IQ (VIQ), Performance IQ (PIQ), and a Full Scale IQ (FIQ), as well as three index scores. In this study, we used a short version of the WAIS-III, which included six subtests (Picture Completion, Digit Symbol-Coding, Similarities, Block Design, Digit Span, and Information). The WAIS-III was locally validated and has shown good reliability and validity [29].

\section{Wisconsin Card Sorting Test (WCST)}

The WCST was designed to assess the ability to form abstract concepts, to shift and to maintain cognitive sets, and to utilize feedback [27]. At first, four stimulus cards were presented to the subject. The subject was then given a stack of additional cards and asked to match each one to one of the stimulus cards. The subject was not told about the rule to match the cards; however, he or she was told whether a particular match was right or wrong. A number of different 
scores were generated from their performances; these were: categories completed, trials to complete first category, perseverative errors, failure to maintain set, percent conceptual level responses, total errors, perseverative responses, nonperseverative errors, and conceptual level responses. The WCST was locally validated and shown has good reliability and validity [30].

\section{Purdue Pegboard Test (PPT)}

The PPT is a test designed to evaluate fine motor speed and finger dexterity [27]. Subjects were asked to place pegs into holes as quickly as possible, first with each hand and then with both hands. The total numbers of pegs completed were scored.

\section{Trail making Test, Part A and Part B (TMT-A and TMT-B)}

The TMT was designed to measure psychomotor speed, and visual search and set-shifting abilities [27]. The TMT-A assessed simple psychomotor speed, and consisted of circles that were numbered from 1 to 25 and were randomly distributed across an A4 size page. Subjects were asked to draw a line from circle number 1 to circle number 2 and so on, as fast as possible. TMT-B assessed complex cognitive processing speed and mental flexibility. On the TMT-B, the circles contained both numbers and letters. Subjects were asked to switch between the sequences of numbers and letters by drawing a line from 1 to $\mathrm{A}$, A to 2, 2 to $\mathrm{B}$, and so on, as quickly as possible. For both parts, scoring is expressed in terms of the time in seconds to complete the task.

\section{Stroop Test}

The Stroop test was designed to measure a subject's ability to inhibit automatic response [27]. The test materials, including some color names (red, blue, green and yellow) printed in non matching colored ink, were presented on a computer monitor. Subjects were asked to name the colors as quickly as they could. Both reaction time and percent of correct responses were recorded for analyses.

\section{STATISTICAL ANALYSIS}

T-tests were conducted to compare demographic data and the subjective cognitive measures between OSA patients and control subjects. ANOVA was conducted to the multiple comparison of objective tests measures. The Pearson coefficient was used for the correlation analysis between the objective and subjective measurements. Statistical analyses were carried out using SPSS version 15 software.

\section{RESULTS}

\section{Group Differences on Objective Measures}

In the neurocognitive tests, the OSA patients performed significantly worse than the controls on some of the tests (see Table 2). On the WMS-III, OSA patients showed a significantly decreased performance on the auditory immediate memory scale score $(F(1,34)=6.10 ; p=.02)$ and auditory delayed memory scale score $(\mathrm{F}(1,34)=4.23 ; \mathrm{p}=.05)$. On the WAIS-III, OSA patients showed significantly decreased performance on the Similarities subtests $(F(1,34)=4.65 ; p=.04)$. On the Wisconsin Card Sorting Test, OSA patients showed significantly decreased performance on four index scores, including categories completed $(\mathrm{F}(1,34)=4.01 ; \mathrm{p}=.05)$, conceptual level responses $(\mathrm{F}(1,34)=7.77 ; \mathrm{p}=.01)$, total errors $(\mathrm{F}(1,34)=8.68 ; \quad \mathrm{p}=.01)$ and non-perseverative errors $(\mathrm{F}(1,34)=8.12 ; \mathrm{p}=.01)$. On the Purdue Pegboard Test, OSA patients showed significantly decreased performance for the non-dominant hand $(\mathrm{F}(1,34)=5.81 ; \mathrm{p}=.02)$ and both hands $(F(1,34)=8.77 ; p=.01)$. There were no significant differences between the OSA patients and the controls on the rest of the tests.

Considering circadian effects on subjects' cognitive tests performance, we also compared the tests results between 9 A.M and 2 P.M groups. No significant difference was found.

\section{Group Differences on Subjective Measures}

The OSA patients showed significant higher daytime sleepiness than the control subjects (OSA: $12.56 \pm 2.38$; Control: $\left.5.75 \pm 3.04 ; \mathrm{t}_{(36)}=35.34, \mathrm{p}<.00\right)$. The OSA patients' selfrating of cognitive impairments on the SCIRS were significantly higher than the control subjects on the "attention \& vigilance" $(\mathrm{t}(38)=2.59 ; \mathrm{p}=.01)$, "memory \& learning" $(\mathrm{t}(38)=2.43 ; \mathrm{p}=.02)$, and "emotional control \& motivation" subscales $(\mathrm{t}(38)=2.63 ; \mathrm{p}=.01)$. There was no significant difference between the two groups on the "abstract thinking \& problem solving" subscales (see Table $\mathbf{3}$ ).

\section{Correlational Analyses: The Association between Objective and Subjective Measures}

There was no significant correlation coefficient between neurocognitive tests scores and SCIRS subscales for both groups Table 4.

\section{DISCUSSION}

The goals of the present study were to assess the objective performance and subjective ratings of cognitive functions in OSA patients, and to examine the relationship between the objective and subjective measures of neurocognitive functions. On the neurocognitive tests, OSA patients displayed significantly decreased performance on executive function, auditory memory and non-dominant hand dexterity. The results are generally consistent with findings of previous studies. Executive function was one of the neurocognitive functions that was most consistently shown to be impaired in OSA patients. Poor executive function may affect OSA patients' logical thinking, judgment, and decision making in their daily life.

The other consistent finding is that OSA patients demonstrated decreased performance in auditory memory [31]. Some research has indicated that the hippocampus is the area in the brain most vulnerable to acute and transient hypoxemia [32]. It is possible that frequent nocturnal hypoxemia may lead to memory impairment through an affect on the hippocampus. Poor memory may interfere with many aspects of daily living activities and reduce the quality of life.

However, our results showed no significant difference between the two groups in their level of vigilance as assessed by the MVT. Although there were exceptions [33-36], the majority of previous studies demonstrated decreased attention in OSA patients. One possible explanation for the negative result in our study is the sequence of the test administration. 
Table 2. Means, Standard Deviations and ANOVA Results on Neurocognitive Tests

\begin{tabular}{|c|c|c|c|c|c|}
\hline Neurocognitive tests & OSA Patients $\mathrm{M} \pm \mathrm{SD}$ & Control Subjects $\mathrm{M} \pm \mathrm{SD}$ & $\mathbf{F}$ & df & $P$ value \\
\hline \multicolumn{6}{|c|}{ MVT } \\
\hline Reaction time & $0.68 \pm 0.88$ & $0.71 \pm 0.13$ & .46 & 1,34 & 0.50 \\
\hline Number of misses & $4.28 \pm 6.10$ & $4.12 \pm 7.73$ & .01 & 1,34 & 0.95 \\
\hline Number of false alarms & $11.78 \pm 13.14$ & $5.82 \pm 6.38$ & 2.85 & 1,34 & 0.10 \\
\hline \multicolumn{6}{|c|}{ PASAT } \\
\hline Total number of correct & $0.74 \pm 0.12$ & $0.77 \pm 0.11$ & .59 & 1,34 & 0.45 \\
\hline \multicolumn{6}{|c|}{ WMS (scale score) } \\
\hline Auditory immediate memory & $17.28 \pm 4.71$ & $20.58 \pm 3.34$ & 6.10 & 1,34 & $0.02 *$ \\
\hline Visual immediate memory & $17.61 \pm 3.68$ & $18.32 \pm 3.38$ & .37 & 1,34 & 0.55 \\
\hline Immediate memory & $35.44 \pm 6.57$ & $38.90 \pm 5.90$ & 2.83 & 1,34 & 0.10 \\
\hline Auditory delayed memory & $17.83 \pm 5.60$ & $21.00 \pm 3.61$ & 4.23 & 1,34 & $0.05 *$ \\
\hline Visual delayed memory & $17.00 \pm 3.91$ & $17.79 \pm 4.30$ & .34 & 1,34 & 0.56 \\
\hline Auditory recognition delayed memory & $14.89 \pm 23.85$ & $10.47 \pm 2.70$ & .64 & 1,34 & 0.43 \\
\hline General Memory & $46.83 \pm 13.81$ & $49.26 \pm 8.72$ & .41 & 1,34 & 0.52 \\
\hline \multicolumn{6}{|c|}{ WAIS-III (scale score) } \\
\hline Picture Completion & $11.22 \pm 2.49$ & $11.37 \pm 2.09$ & .04 & 1,34 & 0.85 \\
\hline Digit Symbol-Coding & $10.94 \pm 2.16$ & $16.37 \pm 8.77$ & 1.48 & 1,34 & 0.23 \\
\hline Similarities & $11.33 \pm 2.61$ & $12.84 \pm 1.54$ & 4.65 & 1,34 & $.04 *$ \\
\hline Block Design & $11.61 \pm 1.98$ & $12.16 \pm 2.29$ & .60 & 1,34 & 0.44 \\
\hline Digit Span & $10.72 \pm 2.76$ & $13.37 \pm 2.31$ & 1.03 & 1,34 & 0.32 \\
\hline Information & $11.78 \pm 2.76$ & $13.37 \pm 2.31$ & 3.03 & 1,34 & 0.07 \\
\hline \multicolumn{6}{|c|}{ WCST } \\
\hline Categories completed & $3.39 \pm 3.15$ & $5.42 \pm 3.02$ & 4.01 & 1,34 & $0.05 *$ \\
\hline Trials to complete first category & $35.93 \pm 31.35$ & $28.58 \pm 23.65$ & 0.61 & 1,34 & 0.44 \\
\hline Perseverative errors & $27.83 \pm 16.09$ & $19.53 \pm 10.08$ & 3.59 & 1,34 & 0.07 \\
\hline Failure to maintain set & $1.11 \pm 1.57$ & $1.48 \pm 1.26$ & 0.60 & 1,34 & 0.44 \\
\hline Percent conceptual level responses & $41.29 \pm 26.53$ & $61.72 \pm 17.34$ & 7.77 & 1,34 & $.01 * *$ \\
\hline Total errors & $57.61 \pm 26.09$ & $37.42 \pm 14.17$ & 8.68 & 1,34 & $.01 * *$ \\
\hline Perseverative responses & $31.44 \pm 20.55$ & $21.68 \pm 12.42$ & 3.10 & 1,34 & .09 \\
\hline Non-perseverative errors & $29.61 \pm 16.44$ & $17.89 \pm 6.98$ & 8.12 & 1,34 & $.01^{*}$ \\
\hline \multicolumn{6}{|l|}{ PPT } \\
\hline Dominant hand & $14.33 \pm 1.61$ & $15.05 \pm 2.07$ & 4.78 & 1,34 & 0.25 \\
\hline Non-dominant hand & $13.28 \pm 1.60$ & $14.57 \pm 1.68$ & 5.81 & 1,34 & $0.02 *$ \\
\hline Both hands & $22.22 \pm 3.08$ & $25.32 \pm 3.27$ & 8.77 & 1,34 & $0.01 *$ \\
\hline $\begin{array}{c}\text { TMT-A } \\
\text { Completion time (Sec.) }\end{array}$ & $31.57 \pm 10.33$ & $27.32 \pm 7.49$ & 2.06 & 1,34 & 0.16 \\
\hline TMT-B & & & & & \\
\hline Completion time (Sec.) & $75.51 \pm 27.36$ & $65.37 \pm 20.23$ & 1.66 & 1,34 & 0.21 \\
\hline \multicolumn{6}{|c|}{ Stroop Test } \\
\hline Reaction time (Sec.) & $0.74 \pm 0.16$ & $0.79 \pm 0.20$ & 0.75 & 1,34 & 0.39 \\
\hline Percent of correct responses & $97.07 \pm 3.87$ & $97.07 \pm 4.90$ & 0.01 & 1,34 & 0.92 \\
\hline
\end{tabular}


Table 3. Means, Standard Deviation and t-test on the Subjective Cognitive Impairment Rating Scale (SCIRS)

\begin{tabular}{|c|c|c|c|c|}
\hline Subscale & OSA Patients & Control Subjects & t Value & $p$ Value \\
\hline Attention \& Vigilance & $2.24 \pm 0.96$ & $1.32 \pm 0.93$ & 2.99 & $.01 *$ \\
\hline Memory \& Learning & $3.11 \pm 1.58$ & $1.83 \pm 1.09$ & 2.88 & $.01 *$ \\
\hline Abstract thinking \& Problem solving & $2.57 \pm 1.54$ & $1.56 \pm 0.96$ & 1.80 & .07 \\
\hline Emotional control \& Motivation & $2.74 \pm 1.33$ & $1.51 \pm 0.83$ & 3.41 & $.00 *$ \\
\hline
\end{tabular}

$* p<.05$

Table 4. Correlation Between Subjective and Objective Measures

\begin{tabular}{|c|c|c|c|c|c|c|}
\hline \multirow[b]{2}{*}{ Neurocognitive Tests } & \multicolumn{6}{|c|}{ SCIRS } \\
\hline & & $\begin{array}{l}\text { Attention \& } \\
\text { Vigilance }\end{array}$ & $\begin{array}{l}\text { Memory \& } \\
\text { Learning }\end{array}$ & $\begin{array}{l}\text { Abstract Think- } \\
\text { ing \& Problem } \\
\text { Solving }\end{array}$ & $\begin{array}{l}\text { Emotional Control } \\
\text { \& Motivation }\end{array}$ & Total score \\
\hline \multicolumn{7}{|c|}{ MVT } \\
\hline \multirow{2}{*}{ Reaction time } & $\mathrm{O}$ & -.02 & -.08 & .05 & -.06 & -.06 \\
\hline & $\mathrm{C}$ & .03 & .23 & .15 & .40 & .21 \\
\hline \multirow{2}{*}{ Number of misses } & $\mathrm{O}$ & -.13 & -.10 & -.02 & -.07 & -.08 \\
\hline & $\mathrm{C}$ & -.20 & -.08 & -.04 & .00 & -.09 \\
\hline \multirow{2}{*}{ Number of false alarms } & $\mathrm{O}$ & -.21 & -.38 & -.44 & -.30 & -.37 \\
\hline & $\mathrm{C}$ & .14 & .24 & -.47 & .35 & .32 \\
\hline \multicolumn{7}{|c|}{ PASAT } \\
\hline \multirow{2}{*}{ Total number of correct } & $\mathrm{O}$ & .30 & .18 & .21 & .23 & .24 \\
\hline & $\mathrm{C}$ & .03 & -.00 & -.15 & -.14 & -.07 \\
\hline \multicolumn{7}{|c|}{ WMS } \\
\hline \multirow{2}{*}{ Auditory immediate memory } & $\mathrm{O}$ & .33 & .17 & .35 & .35 & .31 \\
\hline & $\mathrm{C}$ & .16 & .29 & -.03 & .17 & .16 \\
\hline \multirow{2}{*}{ Visual immediate memory } & $\mathrm{O}$ & .46 & .48 & .49 & .43 & .41 \\
\hline & $\mathrm{C}$ & -.24 & .05 & -.29 & .08 & -.11 \\
\hline \multirow{2}{*}{ Immediate memory } & $\mathrm{O}$ & .32 & .30 & .46 & .46 & .41 \\
\hline & $\mathrm{C}$ & .04 & .19 & -.19 & .14 & .03 \\
\hline \multirow{2}{*}{ Auditory delayed memory } & $\mathrm{O}$ & .16 & -.03 & .14 & .13 & .10 \\
\hline & $\mathrm{C}$ & .19 & .39 & .05 & .32 & .26 \\
\hline \multirow{2}{*}{ Visual delayed memory } & $\mathrm{O}$ & .47 & .51 & .52 & .54 & .53 \\
\hline & $\mathrm{C}$ & -.31 & .00 & -.30 & -.07 & -.18 \\
\hline \multirow{2}{*}{$\begin{array}{l}\text { Auditory recognition delayed } \\
\text { memory }\end{array}$} & $\mathrm{O}$ & .38 & .29 & .34 & .25 & .33 \\
\hline & $\mathrm{C}$ & -.01 & -.04 & -.34 & -.20 & -.16 \\
\hline \multirow{2}{*}{ General Memory } & $\mathrm{O}$ & .29 & .23 & .07 & .19 & .20 \\
\hline & $\mathrm{C}$ & -.08 & .15 & -.23 & .04 & -.03 \\
\hline \multicolumn{7}{|c|}{ WAIS-III } \\
\hline \multirow{2}{*}{ Picture Completion } & $\mathrm{O}$ & .31 & .03 & .23 & .13 & .17 \\
\hline & $\mathrm{C}$ & -.15 & -.14 & -.35 & -.04 & -.19 \\
\hline \multirow{2}{*}{ Digit Symbol-Coding } & $\mathrm{O}$ & .19 & -.18 & -.14 & -.18 & -.11 \\
\hline & $\mathrm{C}$ & -.18 & -.01 & -.16 & .04 & -.08 \\
\hline \multirow{2}{*}{ Similarities } & $\mathrm{O}$ & .22 & .03 & .12 & .18 & .13 \\
\hline & $\mathrm{C}$ & .05 & .04 & -.10 & -.11 & -.02 \\
\hline
\end{tabular}


Table 4. contd...

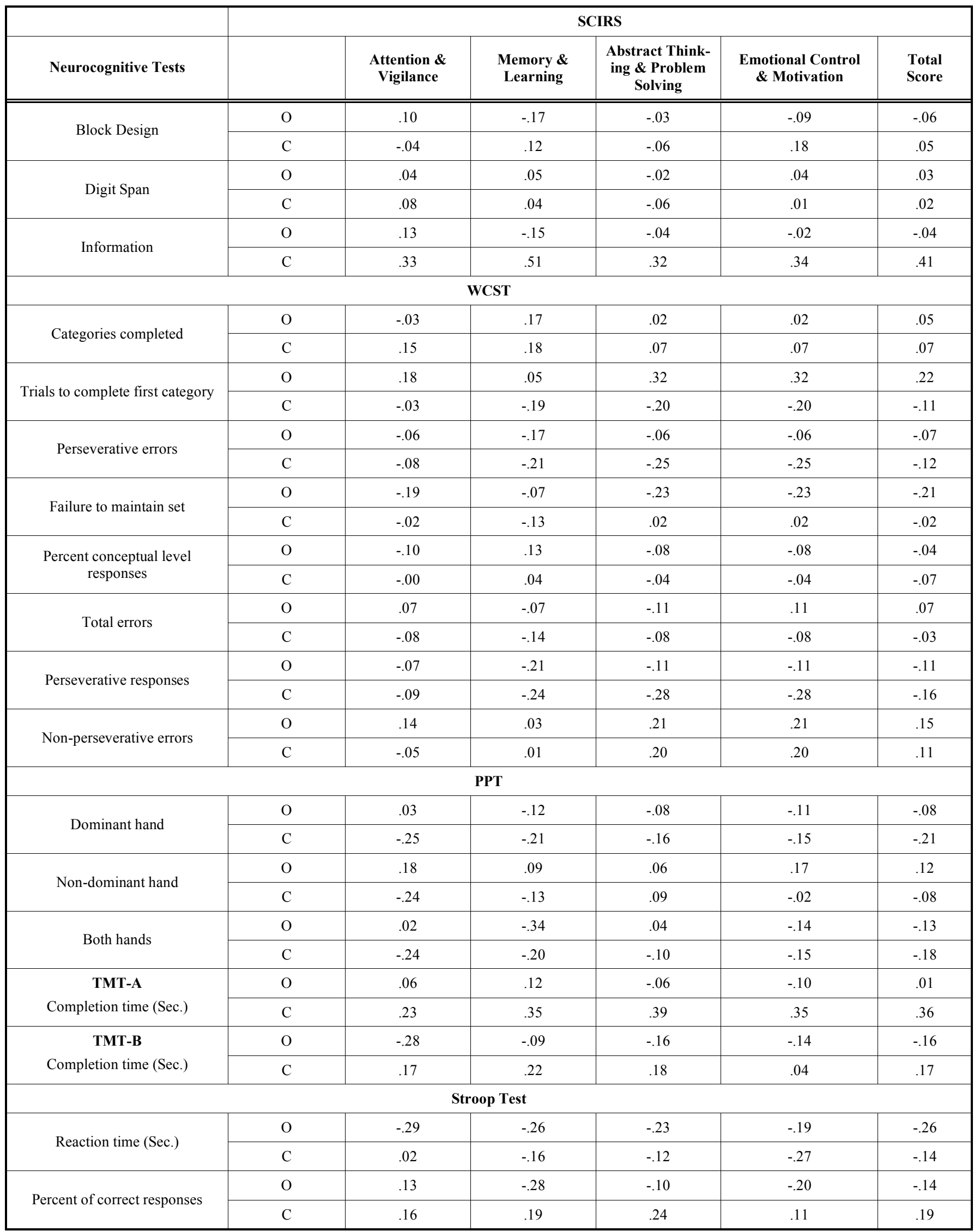

O OSA group; C: Control group 
The MVT was the first test in the neurocognitive test battery to be administered. Since the patients might still be able to maintain concentration at the beginning of the test session, the discerning capability may not be enough to differentiate OSA patients. Further studies may consider the effect of time serial and randomly assign the testing order in the neurocognitive test battery. The other possible explanation is the index of MVT simplified the concept of attention. Most OSA patients exhibit a broad range of attention deficits, beyond impaired maintenance of wakefulness. A specific battery of tests may need to correctly assess OSA patients' attention deficit.

In terms of the subjective evaluation of cognitive function related to daily living activities, it was interesting to see that OSA patients rated themselves as having more impairments than normal control subjects in all the areas except for "abstract thinking and problem solving". OSA patients may perceive impairments in their attention, memory, and emotional control, but not in their abilities related to executive functions. It is important to note that OSA patients showed decreased performance on the tests of executive function, but reported no significant impact on their abilities in the associated areas. This discrepancy may reflect an absence of awareness of their executive function impairment. The majority of OSA patients are middle-aged. Many of them are working as professionals or managers. Impairment in executive function could have a great impact on their daily life functioning, so an increased awareness of their cognitive impairments could be beneficial. In addition, as mentioned above, an awareness of the negative impact of OSA may enhance the patients' compliance with CPAP treatment. The inclusion of a neurocognitive assessment in the evaluation of OSA patients should be considered.

\section{CONCLUSION AND TRIAL REGISTRATION}

There are some limitations to this study. First, the small male sample size may limit the representation of the sample and the statistical authority. Our results must be considered preliminary. Future studies with a larger sample size should be conducted to replicate the findings. Second, the lack of norms in some of the neurocognitive tests may have limited the interpretation of the results. Although a decrease in functioning could be evidenced through the comparisons between the groups, the degree of impairment in relation to the general population could not be assumed. Third, all subjects in the present study are male subjects. The results may portray a complete picture of OSA patients, and also limit the external validity. Further study should include female subjects and compared the results. Finally, we didn't use a depression questionnaire to evaluate the emotion effect on neurocognitive tests performance. However, the two groups didn't show significant different on SF-36 "Mental Health" subscale (OSA:63.33 \pm 18.47 ; Controls: $71.17 \pm 10.55 ; \mathrm{t}(36)=1.593, \mathrm{p}=0.12$. We speculate the difference between the two groups of the neurocognitive tests may not be caused by emotional states.

In summary, the present study found that OSA indeed impairs patients' cognitive performance; however, patients may not be aware of it. The results indicate that in clinical practice, an evaluation of neurocognitive function may be important. Neurocognitive tests can not only provide information for understanding the pathology, but also reflect functional performance. Neurocognitive tests can also provide feedback to OSA patients, and therefore may facilitate future treatment.

\section{CONFLICT OF INTEREST}

The authors confirm that this article content has no conflicts of interest.

\section{ACKNOWLEDGEMENT}

Declared none.

\section{APPENDIX I}

\section{The Subjective Cognitive Impairment Rating Scale}

The purpose of this rating scale is to find out how, in your opinion, sleep apnea has affected your life in the last month. It will be helpful for your physician to understand your feelings and the changes you have experienced while undergoing treatment.

There are some symptoms that sleep apnea patients frequently suffer. Please read the following items and mark those that are applicable to you. If you are unsure, try to mark the answer that most closely describes your experience.

\section{How Does Sleep Apnea Impact Your Life? Do you Agree or Disagree with this Statement?}

\begin{tabular}{|c|c|c|c|c|c|}
\hline I. Attention and Vigilance: & $\begin{array}{c}\text { 0 No Impact Strongly } \\
\text { Disagree }\end{array}$ & 1 Mild Impact & 2 Moderate Impact & $\begin{array}{c}3 \text { Severe Impact } \\
\text { Agree }\end{array}$ & $\begin{array}{l}4 \text { Extreme Impact } \\
\text { Strongly Agree }\end{array}$ \\
\hline $\begin{array}{l}\text { 1. I have difficulty concentrating. People or things } \\
\text { around me can easily distract me. }\end{array}$ & & & & & \\
\hline $\begin{array}{l}\text { 2. I often forget the things that others asked me to do a } \\
\text { few minutes ago, such as relaying a message. }\end{array}$ & & & & & \\
\hline $\begin{array}{l}\text { 3. My mind wanders. I cannot remain focused on what } \\
\text { someone is saying in a meeting. }\end{array}$ & & & & & \\
\hline $\begin{array}{l}\text { 4. I often hear but pay no attention, e.g., can't hear } \\
\text { others call self while watching TV. }\end{array}$ & & & & & \\
\hline $\begin{array}{l}\text { 5. I am frequently distracted, e.g., failing to notice po- } \\
\text { tentially hazardous traffic situations. }\end{array}$ & & & & & \\
\hline
\end{tabular}


6. My reaction time is slower, e.g., late braking when driving.

II. Memory and Learning ability:

\begin{tabular}{|c|c|c|c|c|c|}
\hline \multicolumn{6}{|l|}{ 1. My memory is worse than before. } \\
\hline \multicolumn{6}{|l|}{ 2. I forget what I have just read. } \\
\hline \multicolumn{6}{|l|}{$\begin{array}{l}\text { 3. I can't remember the name of the person, who has } \\
\text { just been introduced to me. }\end{array}$} \\
\hline \multicolumn{6}{|l|}{$\begin{array}{l}\text { 4. I often forget where my personal belongings are, such } \\
\text { as money, ID card. }\end{array}$} \\
\hline \multicolumn{6}{|l|}{$\begin{array}{l}\text { 5. I can't remember the content of the important conver- } \\
\text { sation that I had just a few days ago. }\end{array}$} \\
\hline \multicolumn{6}{|l|}{$\begin{array}{l}\text { 6. I can't remember things that happened a few days } \\
\text { ago. }\end{array}$} \\
\hline \multicolumn{6}{|l|}{$\begin{array}{l}\text { 7. I can't remember some operational procedures, such } \\
\text { as how to tie my shoelaces, or I forget that I have put } \\
\text { salt/pepper on my food. }\end{array}$} \\
\hline III. Executive function: & $\begin{array}{l}\text { 0 No Impact } \\
\text { StronglyDisagree }\end{array}$ & 1 Mild Impact & 2 Moderate Impact & $\begin{array}{c}3 \text { Severe Impact } \\
\text { Agree }\end{array}$ & $\begin{array}{l}4 \text { Extreme Impact } \\
\text { Strongly Agree }\end{array}$ \\
\hline \multicolumn{6}{|l|}{$\begin{array}{l}\text { 1. I have difficulty following the plot of a book or } \\
\text { movie. }\end{array}$} \\
\hline \multicolumn{6}{|l|}{$\begin{array}{l}\text { 2. I have difficulty weighing the pros and cons of a } \\
\text { situation and frequently make poor decisions. }\end{array}$} \\
\hline \multicolumn{6}{|l|}{$\begin{array}{l}\text { 3. I don't easily come up with alternative solutions to } \\
\text { problems. }\end{array}$} \\
\hline \multicolumn{6}{|l|}{ 4. I make the same mistakes repeatedly. } \\
\hline \multicolumn{6}{|l|}{$\begin{array}{l}\text { 5. My ability to analyze a problem (break it down) is } \\
\text { not as good as before. }\end{array}$} \\
\hline \multicolumn{6}{|l|}{ 6. I can't organize new information well. } \\
\hline $\begin{array}{l}\text { 7. When confronting a problem, I frequently get bogged } \\
\text { down with details (can't see the "big picture" or take a } \\
\text { different angle). }\end{array}$ & & & & & \\
\hline
\end{tabular}

IV. Emotional Control and Motivation:

\begin{tabular}{|l|l|l|l|l|}
\hline $\begin{array}{l}\text { 1. I get angry for no reason, e.g., shout at my children or } \\
\text { partner for no reason. }\end{array}$ & & & & \\
\hline 2. I suffer from mood swings. & & & & \\
\hline 3. I have become impatient. & & & & \\
\hline 4. I have no interest in day-to-day activities. & & & & \\
\hline 5. I am not curious. & & & & \\
\hline $\begin{array}{l}\text { 6. Things that interested me before, no longer sustain } \\
\text { my interest. }\end{array}$ & & & & \\
\hline 7. I find it difficult to persevere in solving problems. & & & & \\
\hline $\begin{array}{l}\text { 8. When confronting a difficult work or academic situa- } \\
\text { tion, I often give up and don't like to ask for help. }\end{array}$ & & & & \\
\hline
\end{tabular}

\section{REFERENCES}

[1] Engleman HM, Asgari-Jirhandeh N, McLeod AL, Ramsay CF, Deary IJ, Douglas NJ. Self-reported use of CPAP and benefits of CPAP therapy: a patient survey. Chest 1996; 109: 1470-6.

[2] Guilleminault C, Bassiri A. In: Kryger MH, Roth T, Dement WC, Ed. Principles and practice of sleep medicine. Philadelphia: Elsevier Saunders 2005; pp. 1043-52.

[3] Young T, Palta M, Dempsey J, Skatrud J, Weber S, Badr S. The occurrence of sleep-disordered breathing among middle-aged adults. N Engl J Med 1993; 328: 1230-5.
[4] Kales A, Cadieux RJ, Bixler EO, et al. Severe obstructive sleep apnea--I: Onset, clinical course, and characteristics. J Chronic Dis 1985; 38: 419-25.

[5] Roehrs T, Merrion M, Pedrosi B, Stepanski E, Zorick F, Roth T. Neuropsychological function in obstructive sleep apnea syndrome (OSAS) compared to chronic obstructive pulmonary disease (COPD). Sleep 1995; 18: 382-8.

[6] Engleman HM, Kingshott RN, Martin SE, Douglas NJ. Cognitive function in the sleep apnea/hypopnea syndrome (SAHS). Sleep 2000; 23: S102-8.

[7] Weaver TE. Outcome measurement in sleep medicine practice and research. Part 2: assessment of neurobehavioral performance and mood. Sleep Med Rev 2001; 5: 223-36. 
[8] Bedard MA, Montplaisir J, Richer F, Rouleau I, Malo J. Obstructive sleep apnea syndrome: pathogenesis of neuropsychological deficits. J Clin Exp Neuropsychol 1991; 13: 950-64.

[9] Findley LJ, Barth JT, Powers DC, Wilhoit SC, Boyd DG, Suratt PM. Cognitive impairment in patients with obstructive sleep apnea and associated hypoxemia. Chest 1986; 90: 686-90.

[10] Naegele B, Thouvard V, Pepin JL, et al. Deficits of cognitive executive functions in patients with sleep apnea syndrome. Sleep 1995; $18: 43-52$

[11] Kim HC, Young T, Matthews CG, Weber SM, Woodward AR, Palta M. Sleep-disordered breathing and neuropsychological deficits. A population-based study. Am J Respir Crit Care Med 1997; 156: 1813-9.

[12] Bohnen N, Jolles J, Twijnstra A, Mellink R, Wijnen G. Late neurobehavioural symptoms after mild head injury. Brain Injury 1995; 9: 27-34.

[13] Raskin SA, Mateer CA, Tweeten R. Neuropsychological assessment of individuals with mild traumatic brain injury. ClinNeuropsychol 1998; 12: 21-30.

[14] Gass CS, Apple C. Cognitive complaints in closed-head injury: relationship to memory test performance and emotional disturbance.J Clin Exp Neuropsychol 1997; 19: 290-9.

[15] Satz P, Forney DL, Zaucha K, et al. Depression, cognition, and functional correlates of recovery outcome after traumatic brain injury. Brain Injury 1998; 12: 537-53.

[16] Bastien CH, Fortier-Brochu É, Rioux I, LeBlanc M, Daley M, Morin CM. Cognitive performance and sleep quality in the elderly suffering from chronic insomnia: relationship between objective and subjective measures. J Psychosom Res 2003; 54: 39-49.

[17] Hoffstein V, Szalai JP. Predictive value of clinical features in diagnosing obstructive sleep apnea. Sleep 1993; 16: 118-22.

[18] Maislin G, Pack AI, Kribbs NB, et al. A survey screen for prediction of apnea. Sleep 1995; 18: 158-66.

[19] Gliklich RE, Wang PC. Validation of the snore outcomes survey for patients with sleep-disordered breathing. Arch Otolaryngol Head Neck Surg 2002; 128: 819-24.

[20] Chen NH, Li HY, Gliklich RE, Chu CC, Liang SC, Wang PC. Validation assessment of the Chinese version of the Snore Outcomes Survey. Qual Life Res 2002; 11: 601-7.

[21] Jan YW, Chen CW, Chen NH. The subjective cognitive impairment rating scale (SCIRS): an instrument for self evaluation of cognitive impairments in patients with sleep spnea. Sleep 2003; 27; A678.
[22] Gottlieb DJ, Whitney CW, Bonekat WH, et al. Relation of sleepiness to respiratory disturbance index: the sleep heart health study. Am J Respir Crit Care Med 1999; 159: 502-7.

[23] Ware JE Jr, Sherbourne CD. The MOS 36-item short-form health survey (SF-36). I. Conceptual framework and item selection. Med Care 1992; 30: 473-83

[24] Hirskowitz M, De La Cueva L, Herman JH. The multiple vigilance test. Behav Res Methods Instrum Comput 1993; 25: 272-5.

[25] Yang $\mathrm{CM}, \mathrm{Wu} \mathrm{CS}$. The sleep and cognitive function in chronic fatique patients: National science council Taiwan 2000.

[26] Chen S, Huang J, Dorflinger J, Zaferos J, Durgerian S, Rao S Teasing apart the paced auditory serial addition task (PASAT): an fMRIstudy: National science council Taiwan 2007.

[27] Spreen O, Strauss E. A compendium of neuropsychological tests: administration, norms, and commentary. $2^{\text {nd }}$ ed. New York: Oxford University Press 1998

[28] Lin KN, Chu YC, Yang CC, Cheng TW, Chu FH, Hua MS. The development and current achievement of clinical neuropsychology in Taiwan. Res App Psychol 2008: 121-39.

[29] Chen HY. The Estimated administration time and related factors for the wechsler adult intelligence scale $3^{\text {rd }}$ ed. (WAIS-III) in Taiwan. Psychol Test 2002; 49: 39-50.

[30] Lin CCH, Chen WJ, Yang HJ, Hsiao CK, Tien AY. Performance on the Wisconsin card sorting test among adolescents in Taiwan: norms, factorial structure, and relation to schizotypy. J Clin Exp Neuropsychol 2000; 22: 69-79.

[31] Fulda S, Schulz H. Cognitive dysfunction in sleep-related breathing disorders: a meta-analysis. Sleep Res Online 2003; 5: 19-51.

[32] Caine D, Watson JD. Neuropsychological and neuropathological sequelae of cerebral anoxia: a critical review. J Int Neuropsychol Soc 2000; 6: 86-99.

[33] Kotterba S, Rasche K, Widdig W, et al. Neuropsychological investigations and event-related potentials in obstructive sleep apnea syndrome before and during CPAP-therapy. J Neurol Sci 1998; 159: 45-50.

[34] Sauter C, Asenbaum S, Popovic R, et al. Excessive daytime sleepiness in patients suffering from different levels of obstructive sleep apnoea syndrome. J Sleep Res 2000; 9: 293-301.

[35] Kotterba S, Rasche K, Widdig W, et al. Vigilance and neuropsychological capacity in obstructive sleep apnea syndrome and chronic obstructive pulmonary disease. Somnologie 1998; 2: $117-22$.

[36] Van Son B, Hofman WF, van Uffelen R. Sleep fragmentation, as measured by EEG and PTT arousals, and daytime functioning in OSA patients. J Sleep Res 2000; 9: S199.

(C) Chen et al.; Licensee Bentham Open.

This is an open access article licensed under the terms of the Creative Commons Attribution Non-Commercial License (http://creativecommons.org/licenses/by-nc/3.0/) which permits unrestricted, non-commercial use, distribution and reproduction in any medium, provided the work is properly cited 